\title{
PERFORMANCE-BASED COMPARISON OF DIFFERENT RETROFIT METHODS FOR REINFORCED CONCRETE SRUCTURES
}

\author{
Andrea Miano ${ }^{1}$, Halil Sezen ${ }^{2}$, Fatemeh Jalayer ${ }^{1}$, and Andrea Prota ${ }^{1}$ \\ 1) Department of Structures for Engineering and Architecture, University of Naples "Federico II" \\ Via Claudio 21, 80125, Naples, Italy \\ \{andrea.miano, fatemeh.jalayer, a.prota\}@unina.it \\ ${ }^{2)}$ Department of Civil, Environmental \& Geodetic Engineering, Ohio State University \\ Neil Avenue 2070, 43210, Columbus, Ohio, USA \\ sezen.1@osu.edu
}

Keywords: Performance-based seismic assessment, Seismic retrofit of RC structures, Nonlinear dynamic analysis methods, Flexural-shear-axial load interaction, Bar slip model.

\begin{abstract}
Recent devastating earthquakes around the world have shown the vulnerability and deficiencies of existing reinforced concrete $(R C)$ frame structures. In particular, recent research on seismic risk analysis have highlighted that nonductile concrete frame structures are much more susceptible to collapse than modern code-conforming frames. Therefore, for this type of structures, it is necessary to accurately model materials and members to capture the flexure, shear and flexure-shear failure modes in members and the potential collapse of the structure. In this paper, alternative retrofit methods are evaluated for these older frame buildings using a nonlinear structural performance assessment methodology. As a case study, the longitudinal frame of an existing building is modeled, including the effect of flexural-shearaxial load interaction and the bar slip deformational component in order to be able to capture column shear and axial failures. A probability-based framework is implemented in order to assess the structural performance and safety at each chosen performance level. This study shows that it is crucial to choose the most effective retrofit strategy based on the assessed performance of the bare frame.
\end{abstract}




\section{INTRODUCTION}

Recent devastating earthquakes around the world showed the vulnerability and deficiencies of existing reinforced concrete (RC) frame structures. The research of efficient methods for estimating the collapse risk of these structures is a crucial point in seismic regions [1,2]. This paper focuses on buildings with design details that do not comply with current seismic code requirements and structural members of these buildings include poor reinforcement details such as widely spaced transverse steel with 90-degree end hooks. Post-earthquake reconnaissance and recent research on seismic risk analysis have shown that these nonductile concrete frame structures are much more susceptible to collapse than modern code-conforming frames $[3,4]$. Effective retrofit methods are needed to improve the structural performance of these buildings, preventing collapse. Depending on the desired performance, conventional retrofit methods, such as concrete jacketing of the columns, addition of shear walls or strengthening beams and columns using new materials, e.g., fiber reinforced polymers (FRP), can be used to meet the new seismic code requirements.

In this paper, alternative retrofit methods are evaluated for older nonductile frame buildings using a nonlinear structural performance assessment methodology. Performance-based assessment paradigm has been a persistent research theme over the past decade within the earthquake engineering community in order to develop seismic fragilities for nonductile existing buildings [5-7]. Nonlinear dynamic analysis procedures can be used to perform performance based seismic assessment, using recorded ground motions. These procedures can be used to estimate parameters required for specific probabilistic assessment criteria, such as Demand and Capacity Factored Design (DCFD, [8]), and also to make direct probabilistic performance assessment using numerical methods [8-12]. In particular, Cloud Analysis is chosen here by applying simple regression in the logarithmic space of nonlinear dynamic structural response versus seismic intensity for a set of ground motion records. Cloud Analysis method is particularly efficient since it involves nonlinear analyses of the structure subjected to a set of un-scaled ground motion time histories. The simplicity of its underlying formulation makes it a quick and efficient analysis procedure for fragility assessment and/or performance based safety-checking [5,6,13-15]. Nevertheless, the Cloud Analysis has some limitations, such as the assumption of a constant logarithmic standard deviation for probability distribution of the structural response for a given intensity. Based on this probabilistic nonlinear dynamic analysis framework, a risk based retrofit strategy optimization has been developed in this study. The structural performance is the main parameter taken in to account for the optimization. Following the methods in ASCE 41 [16], three different performance levels have been considered in this work, i.e., immediate occupancy performance level, life safety performance level and collapse prevention performance level.

A seven-story hotel building in Van Nuys, California, is used as a case study in this research. The RC frame building suffered significant damage during the 1994 Northridge earthquake. Detailed seismic evaluations performed by Islam [17] and Browning et al. [18] confirmed structural vulnerability of the nonductile moment frame resisting system of the building. Krawinkler [19] also performed a detailed performance based assessment of the building and compared the effectiveness of different retrofit options. In this research, the north longitudinal frame of the building is modeled, including the effect of flexural-shearaxial load interaction to be able to capture column shear and axial failures.

This study shows that it is crucial to choose the most effective retrofit strategy based on the performance assessment of the bare frame. Each retrofit strategy can lead to different failure mechanisms when the nonductile members are retrofitted to improve their ductility, strength and/or when system ductility is improved while the lateral displacements are limited. 


\section{BUILDING DESCRIPTION AND MODELING}

\subsection{Building description}

One of the longitudinal frames of the seven-story hotel building in Van Nuys, California, is modeled and analyzed in this study. The building is located in the San Fernando Valley of Los Angeles County (34.221 ${ }^{\circ}$ north latitude, $118.471^{\circ}$ west longitude). The frame building was constructed in 1966 according to the 1964 Los Angeles City Building Code. The building was damaged in the M6.7 1994 Northridge earthquake. After the 1994 earthquake, the building was retrofitted with addition of new RC shear walls. Columns in the longitudinal frame are $356 \mathrm{~mm}$ wide and $508 \mathrm{~mm}$ deep, i.e., they are oriented to bend in their weak direction when resisting lateral forces in the plane of the longitudinal frame. Spandrel beams in the north frame are typically $406 \mathrm{~mm}$ wide and $762 \mathrm{~mm}$ deep in the second floor, $406 \mathrm{~mm}$ wide and $572 \mathrm{~mm}$ deep in the third through seventh floors, and $406 \mathrm{~mm}$ by $559 \mathrm{~mm}$ at the roof level. Column concrete has a compressive nominal strength $f^{\prime} c$ of $34.5 \mathrm{MPa}$ in the first story, 27.6 $\mathrm{MPa}$ in the second story, and 20.7 MPa in other floors. Beam and slab concrete strength $f^{\prime}{ }_{c}$ is $27.6 \mathrm{MPa}$ in the second floor and $20.7 \mathrm{MPa}$ in other floors. Grade $60\left(f_{y}=414 \mathrm{MPa}\right)$ reinforcing steel is used in columns. The specified yield strength, $f_{y}$, is $276 \mathrm{MPa}$ (Grade 40 ) for the steel used in beams and slabs. Figure 1 shows the longitudinal frame modeled in this research and some of the damaged columns in this frame after the 1994 Northridge earthquake.

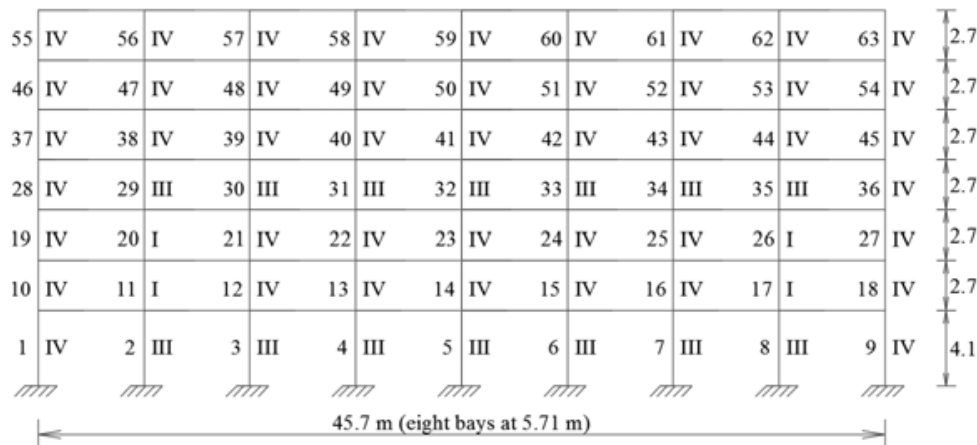
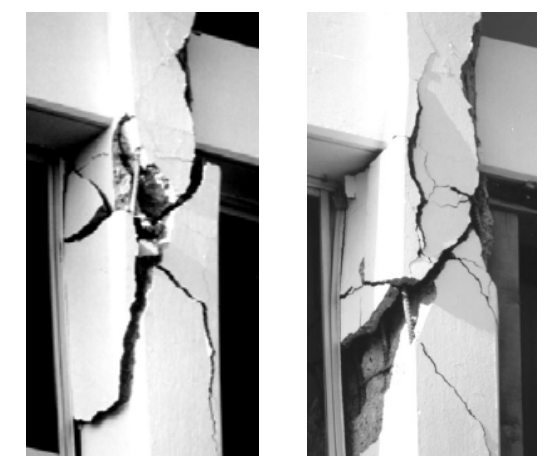

Figure 1 Holiday Inn hotel building longitudinal frame and some of the damaged columns in this frame after the 1994 Northridge earthquake [20]

The column and beam reinforcement details are provided in [19]. In the frame modeled in this study (Figure 1), end columns include eight No.9 longitudinal bars between ground and second floors and six No.7 bars in other stories. The No.3 column ties are spaced at $310 \mathrm{~mm}$ on center between ground and second floors and No.2 ties are spaced at $310 \mathrm{~mm}$ on center above the second floor level. All middle columns are reinforced with ten No.9 longitudinal bars between ground and second floor, six No.9 bars between second and fourth floors and six No.7 bars above the fourth floor (with the exception of columns 11, 17, 20 and 26, reinforced with eight No.9 bars between second and fourth floors). The No.3 and No.2 column ties are spaced at $310 \mathrm{~mm}$ below and above the fourth floor level, respectively. Beams are reinforced with two No.6 longitudinal bars at the bottom, and top reinforcement varies between two No.8 and three No.9. The stirrups are No.3 at $310 \mathrm{~mm}$ on center above the ground.

\subsection{Modeling of materials and building frame}

The Holiday Inn hotel building experienced multiple shear failures in the columns in the fourth story during the 1994 Northridge earthquake [19]. The amount and spacing of the transverse reinforcement in most columns do not meet the requirements of current seismic 
design code. Therefore, for this type of buildings, it is necessary to accurately model materials and column members and to choose the most suitable shear capacity model for assessment in order to capture the different failure modes in columns and the potential collapse of the building [21]. The material and component models implemented in OpenSees [22] can capture the column failures and potential collapse of the frame. In particular, columns with deficient seismic details such as those found in this hotel building are vulnerable to brittle shear or axial failure during earthquakes. Setzler and Sezen [23] presents a procedure to predict an envelope of the cyclic lateral response that includes the lateral displacement and corresponding strength predictions at the peak strength, onset of lateral strength degradation, and loss of axial-loadcarrying capacity. The model also considers the rigid body rotation of the column due to slip of column longitudinal bars from the anchoring concrete. This rotation due to bar slip is not accounted for in flexural analysis, where the column ends are assumed to be fixed. In this work, as in [23], specific rules have been set in order to predict the flexure critical, shear critical and flexure-shear critical failure mechanisms of the members.

\subsubsection{Flexural model}

Unidirectional axial behavior of concrete and steel materials are modeled to simulate the nonlinear response of beams and columns. Concrete material behavior is modeled using the Concrete01 material in OpenSees, which includes zero tensile strength and a parabolic compressive stress-strain behavior up to the point of maximum strength with a linear deterioration beyond peak strength. This model is chosen as the best approximation combining the unconfined concrete material model by [24] in the post peak region and the confined concrete model by [25], where the uniaxial stress-strain relationship includes the effect of confinement provided by transverse reinforcement (as shown in Figure 2 a for $f^{\prime}{ }^{\prime}=20.7 \mathrm{MPa}$ ). Because the transverse reinforcement in beams and columns is relatively low and poorly detailed, all concrete is modeled more close to the unconfined model with peak strength achieved at a strain of 0.002 and minimum post-peak strength achieved at a compressive strain of 0.006 . The corresponding strength at ultimate strain is $0.05 \cdot f^{\prime}{ }_{c}$ for $f^{\prime}{ }^{\prime}=34.5 \mathrm{MPa}$ and $f^{\prime}{ }^{\prime}=27.6 \mathrm{MPa}$ and $0.2 \cdot f^{\prime} c$ for $f^{\prime}{ }^{\prime}=20.7 \mathrm{MPa}$ (as shown in Figure 2a in Concrete01 model). Longitudinal steel behavior is simulated using the Stee102 material in OpenSees. This model includes a bilinear stress-strain envelope with a curvilinear unloading-reloading response under cyclic loading (as shown in Figure $2 b$ ). The previous research indicates that the observed yield strength of reinforcing steel exceeds the nominal strength $(17,19)$. Following the recommendation of [17], yield strength of $345 \mathrm{MPa}(50 \mathrm{ksi})$ and $496 \mathrm{MPa}(72 \mathrm{ksi})$ are used in this research for Grade 40 and Grade 60 steel, respectively. Both Grade 40 and Grade 60 reinforcement are assumed to have a post-yielding modulus equal to $1 \%$ of the elastic modulus, which is assumed to be $200 \mathrm{GPa}$.
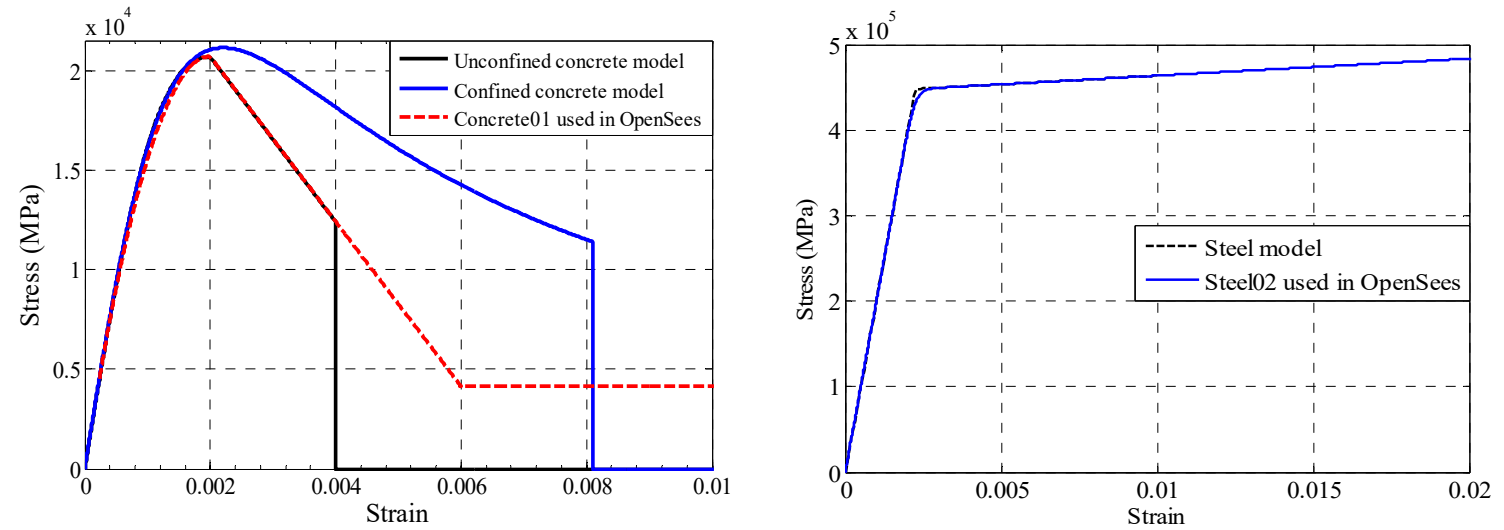

Figure 2 a) Uniaxial stress-strain model relationship for concrete with $f^{\prime}{ }_{c}=20.7 \mathrm{MPa}$ and b) Longitudinal steel stress-strain model relationship for bars with $f_{y}=495 \mathrm{MPa}$ 
Flexural response of beams and columns is simulated using fiber cross sections representing the beam-column line elements. Uniaxial fibers within the gross cross section were assigned to have the property of either concrete (Concrete01 in Figure 2a) or steel (Steel02 in Figure 2b). A typical column cross section included 30 layers of axial fibers in the longitudinal direction of the column. Effective slab width was included in beam cross section. Figure 3 shows the moment-curvature relationship for a selected column (second column on the left in the second story and third column on the left in the third story in Figure 1a), obtained from a fiber cross section analysis. In Figure 3 four critical points in the moment-curvature relationship are shown. The first steel yielding occurred when the bottom tensile layer of steel reached the yield strain of 0.00248 (Figure $2 \mathrm{~b}$ ). Concrete cover spalling occurred when the extreme compressive fiber reached the maximum unconfined concrete axial strain at 0.006 (Concrete01 in Figure 2a). It is assumed that the ultimate flexural deformation capacity is reached when the peak strength is reduced by $20 \%$ at a curvature of approximately $0.1 \mathrm{1} / \mathrm{m}$. The failure of cross section is defined as the axial compressive failure of the last layer of concrete near neutral axis. Beyond the last concrete layer failure, where analysis stops, sectional strength is only contributed by longitudinal steel.

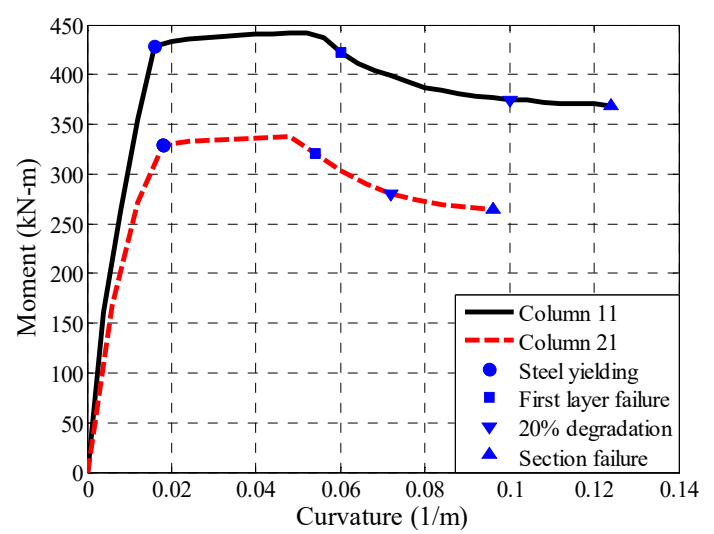

Figure 3 Moment-curvature relationship for a single column (second column on the left in the second story and third column on the left in the third story in Figure 1a)

In OpenSees, flexural beam-column members are modeled as force-based in which a specific moment distribution is assumed along the length of the member. An internal element solution is required to determine member deformations that satisfy the system compatibility.

In force-based column elements, distributed plasticity model is used in OpenSees in order to allow for yielding and plastic deformations at any integration point along the flexural member length under increasing loads. In order to characterize the numerical integration options for the force-based column element and to accurately capture plastic deformations along the members, Newton-Cotes integration [26] is selected in this research. Newton-Cotes method distributes integration points uniformly along the length of the element, including one point at each end of the element (Figure 4a).

Beam member force-deformation response is computed assuming that inelastic action occurs mainly at the member ends and that the middle of the member remains typically elastic, but this is not necessary. Plastic hinge integration methods are used to confine nonlinear deformations in end regions of the element of specified length. The remainder of the element is assumed to stay linear elastic and it is assumed that the length of the plastic region is equal to the depth of the cross-section. The modified Gauss-Radau hinge integration method is used for numerical integration in OpenSees to capture nonlinear deformations near the ends of the force-based beam elements [26]. The modified two-point Gauss-Radau integration within 
each hinge region is implemented at two integration points at the element ends and at $8 / 3$ of the hinge length, $L_{o}=h$, from the end of the element (Figure $4 \mathrm{~b}$ ), where $h$ is the beam depth.

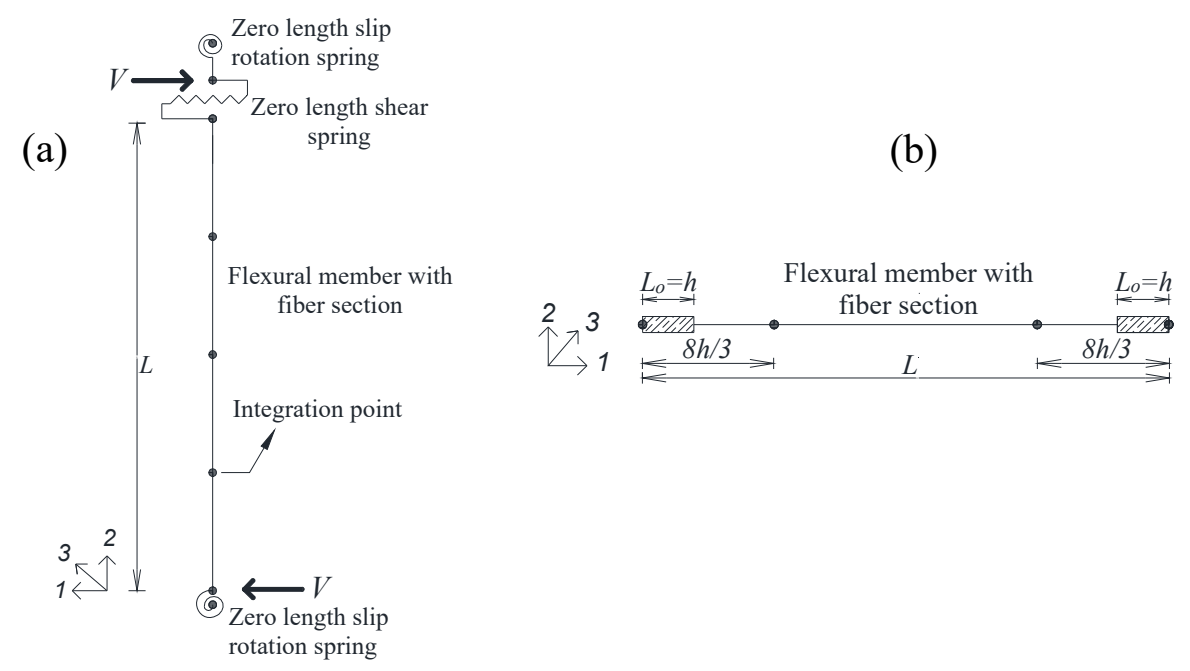

Figure 4 Spring model used for a) column with fixed ends, and b) beam with fixed ends.

\subsubsection{Shear model}

Recent earthquakes have shown that columns in older RC buildings with poor seismic details, including the hotel building considered in this paper, experience shear or flexure-shear failures. The shear model by [23] defines the lateral force-shear displacement envelope includes three distinct points corresponding to: 1) maximum shear strength, 2) onset of shear strength degradation, and 3) axial load failure. The maximum shear strength, $V_{n}$, is predicted using the model by [27]:

$$
V_{n}=V_{s}+V_{c}=k \cdot \frac{A_{v} \cdot f_{y} \cdot d}{s}+k \cdot\left(\frac{0.5 \cdot \sqrt{f_{c}^{\prime}}}{a / d} \cdot \sqrt{1+\frac{P}{0.5 \cdot \sqrt{f_{c}^{\prime}} \cdot A_{g}}}\right) \cdot 0.8 \cdot \mathrm{A}_{\mathrm{g}}
$$

where $A_{v}$ is the transverse reinforcement area within a spacing, $s$, in the loading direction; $f_{y}$ (MPa) is the transverse reinforcement yield strength; $d$ is the effective section depth; $f^{\prime}{ }_{c}$ (MPa) is the compressive strength of concrete; $a$ is the shear span of the element; $P$ is the axial load; $A_{g}$ is the gross area of the section and $k$ is a factor to account for ductility-related strength degradation. Shear displacements are calculated using a combination of two existing models $[23,28]$. The shear displacement corresponding to peak strength, $\Delta_{\mathrm{v}, \mathrm{n}}$, is calculated as:

$$
\Delta_{, n}=\left(\frac{f_{y} \cdot \rho_{l}}{5000 \cdot \frac{a}{d} \cdot \sqrt{\frac{P}{A_{g} \cdot f_{c}^{\prime}}}}-0.0004\right) \cdot L
$$

where $\rho_{l}$ is the longitudinal steel ratio and $L$ is the length of the column.

As described in [28], the procedure for the calculation of shear displacement at the onset of shear failure is adopted from [29]. Shear displacement at axial failure is obtained using the procedure given in [23], which requires the calculation of total lateral displacement. Total lateral drift is calculated using the equation proposed by [30].

\subsubsection{Bar slip model}

When a reinforcing bar embedded in concrete is subjected to a tensile force, strain accumulates over the embedded length of the bar. This tensile strain causes the reinforcing bar to slip 
relative to the concrete in which it is embedded. Slip of longitudinal column bars at column ends (i.e., from the footing or beam-column joint) will cause rigid body rotation of the column. This rotation is not accounted for in flexural analysis, where the column ends are assumed to be fixed. The bar slip model used in this study was originally developed by [29] and presented in [23]. This model assumes a stepped function for bond stress between the concrete and reinforcing steel over the embedment length of the bar. The bond stress is taken as $1 \cdot \sqrt{ } f^{\prime}{ }_{c} \mathrm{MPa}$ for elastic steel strains and as $0.5 \cdot \sqrt{ } f^{\prime}{ }_{c}$ MPa for inelastic steel strains. The rotation due to slip, $\theta_{s}$, is calculated as $\operatorname{slip} /(d-c)$, where slip is the extension of the outermost tension bar from the column end, and $d$ and $c$ are the distances from the extreme compression fiber to the centroid of the tension steel and the neutral axis, respectively. Steel strains and neutral axis location, determined at each step during the moment curvature analysis, are used here to determine slip rotation under increasing moment or column lateral force. The column lateral displacement due to bar slip, $\Delta_{s l i p}$, is equal to the product of the slip rotation and the column length $\left(\Delta_{s l i p}=\theta_{s} \cdot L\right)$.

\subsubsection{Total lateral response}

The total lateral response of a RC column can be modeled using a set of springs in series in OpenSees. The flexure, shear and bar slip deformation models discussed above are each modeled by a spring or element. Each spring is subjected to the same lateral force. Initially, the total displacement response is the sum of the responses of each spring. The combined column spring model is shown in Figure 3. A typical column element includes two zero-length bar slip springs at its ends, one zero-length shear spring and a flexural element with five integration points. The shear behavior is modeled as a uniaxial hysteretic material defined for the spring in the shear direction (i.e., transverse direction of the column or direction 1 in Figure 3). The bar slip rotation is modeled with two rotational springs at the column ends using a uniaxial hysteretic material (i.e., direction 3 in Figure 3). Finally, same vertical displacement is maintained between nodes of zero length elements in the vertical direction (i.e., direction 2 in Figure 3), using the equalDOF option in OpenSees.

The three deformation components are simply added together to predict the total lateral response up to the peak strength of the column [23]. The rules are established for the post-peak behavior of the springs based on a comparison of the shear strength $V_{n}$, the yield strength $V_{y}$ (the shear strength corresponding to moment capacity $M_{y}$ at first longitudinal steel yielding, $\left.V_{y}=2 M_{y} / L\right)$, and the flexural strength $V_{p}\left(V_{p}=2 M_{p} / L\right.$ for a fixed ended column with maximum flexural strength of $M_{p}$ ) required to reach the plastic moment capacity. By comparing $V_{n}, V_{y}$, and $V_{p}$, the columns can be classified into five different categories, as described in [21]: 1) Category I: $V_{n}<V_{y}$ : the shear strength is less than the lateral load causing yielding in the tension steel. The column fails in shear while the flexural behavior remains elastic. As the column strength decreases, shear deformations continue to increase according to the shear model, while the flexure spring unloads along its initial elastic response; 2) Category II: $V_{y}<V_{n}<0.95 \cdot V_{p}$ : the shear strength is greater than the yield strength, but slightly less than the flexural strength of the column. The column fails in shear, but inelastic flexural deformation occurring prior to shear failure affects the post-peak behavior. As the column strength decreases beyond peak strength, shear deformations continue to increase according to the lateral force-displacement shear model, but the flexure and slip springs are locked at their values at peak strength; 3) Category III: $0.95 \cdot V_{p}<V_{n}<1.05 \cdot V_{p}$ : the shear and flexural strengths are very close. As the column strength decreases, all deformations continue to increase according to their individual models; 4) Category IV: $1.05 \cdot V_{p}<V_{n}<1.4 \cdot V_{p}$ : the shear strength is greater than the flexural strength of the column. The column experiences large flexural deformations po- 
tentially leading to a flexural failure. Beyond maximum strength, flexural and slip deformations continue to increase according to their models and inelastic shear deformations can affect the post-peak behavior. Shear failure may occur as displacements increase; 5) Category $\mathrm{V}: V_{n}<1.4 \cdot V_{n}$ : the shear strength is much greater than the flexural strength of the column. The column fails in flexure while the shear behavior remains elastic. If the column strength decreases, flexural and slip deformations continue to increase according to their models, while the shear spring unloads with an unloading stiffness equal to its initial stiffness.

Figure 5 shows the three different deformation components and the total lateral displacement for columns 11 and 21 of the frame (Figure 1a), belonging to two different categories described above (Category I and Category IV). This procedure of comparison and identification of failure mode are repeated for all of the columns of the frame. Table 1 compares $V_{n}, V_{y}$ and $V_{p}$, for the columns in the first four stories, which typically affect the collapse mechanism due to characteristics of the frame.
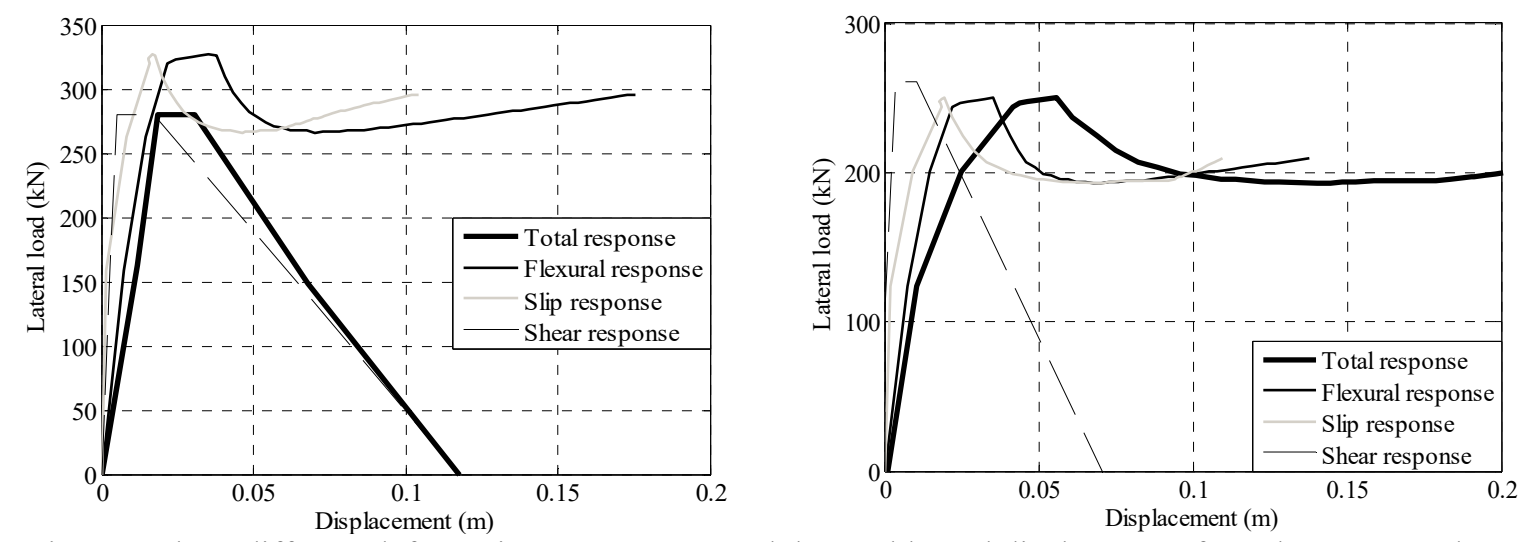

Figure 5 Three different deformation components and the total lateral displacement for columns 11 and 21 of the frame, belonging to Category I (left) and Category IV (right)

\begin{tabular}{|c|c|c|c|c|c|c|c|c|}
\hline \multirow{2}{*}{ Column } & \multicolumn{7}{|c|}{ Bare frame } & \multicolumn{2}{c|}{ Retrofitted frame } \\
\cline { 2 - 9 } & $\begin{array}{c}V_{y} \\
(\mathrm{kN})\end{array}$ & $\begin{array}{c}V_{n} \\
(\mathrm{kN})\end{array}$ & $\begin{array}{c}V_{p} \\
(\mathrm{kN})\end{array}$ & $V_{p} / V_{n}$ & $V_{y} / V_{n}$ & Category & RC jacketing & $\begin{array}{c}\text { FRP } \\
\text { wrapping }\end{array}$ \\
\hline 1,9 & 201 & 233 & 210 & 0.90 & 0.86 & IV & V & V \\
\hline 2,8 & 212 & 245 & 244 & 1.00 & 0.87 & III & V & IV \\
\hline 3 to 7 & 212 & 245 & 244 & 1.00 & 0.87 & III & V & IV \\
\hline 10,18 & 158 & 189 & 176 & 0.93 & 0.84 & IV & IV & V \\
\hline 11,17 & 295 & 279 & 325 & 1.16 & 1.06 & I & IV & IV \\
\hline 12 to 16 & 248 & 281 & 266 & 0.95 & 0.88 & IV & IV & IV \\
\hline 19,27 & 143 & 171 & 162 & 0.95 & 0.84 & IV & IV & V \\
\hline 20,26 & 268 & 260 & 309 & 1.19 & 1.03 & I & IV & IV \\
\hline 21 to 25 & 224 & 260 & 249 & 0.96 & 0.86 & IV & IV & IV \\
\hline 28,36 & 138 & 164 & 154 & 0.94 & 0.84 & IV & IV & V \\
\hline 29,35 & 163 & 175 & 168 & 0.96 & 0.93 & III & IV & V \\
\hline 30 to 34 & 163 & 176 & 168 & 0.96 & 0.93 & III & IV & V \\
\hline
\end{tabular}

Table 1 Comparison of the shear strength Vn, yield strength $\mathrm{Vy}$ and flexural strength $\mathrm{Vp}$ and category classification for the columns in the first four stories in the longitudinal frame

\section{MODELS FOR RETROFITTED FRAMES}

The main goal of the retrofit design is to prevent premature failure of brittle elements and to increase their ductility and strength. In addition, the lateral displacements need to be dis- 
tributed relatively uniformly over the height of the structure to avoid concentration of inelastic deformations in a story mechanism. To control lateral drifts and to keep them below the target displacement, one of the effective strategies for moment frame concrete structures is to add lateral stiffness, e.g., by adding a shear wall, to reduce the period and decrease the resulting building displacements. Another effective way to increase overall ductility and strength of the frame is to increase flexural and shear strength and additional deformation capacity of individual lateral load resistant members. This can be achieved by better confining the columns and shifting the failure mode from brittle shear to ductile flexural mode. Enlarging the cross section of concrete jacketing can increase lateral stiffness and strength and ductility.

The selection of the retrofit scheme and the level of intervention is a rather complex process because many factors need to be considered. To avoid and reduce the restriction of use of building for a long time, addition of new lateral load resistance system, member replacement or local or global modification (addition of stiffness, strength and ductility) of elements and system may be difficult or impossible to implement. The ease and quick application of fiber reinforced polymers (FRP) composite materials makes them attractive for use in structural applications, especially in cases where dead weight, space or time restrictions exist. The goal of this research is to evaluate the effectiveness of common retrofit strategies mainly in terms of improvement of the structural performance. Three different retrofit options are considered: 1) all columns of the frame are RC jacketed, 2) a new shear wall is added to the frame (near the center of the frame and doweled into the existing columns and beams), and 3) all columns of the frame are wrapped by carbon FRP.

\subsection{Reinforced concrete jacketing}

The first retrofit scheme considered is the reinforced concrete jacketing of all columns in the longitudinal frame of the Holiday Inn hotel building. RC jacketing is a traditional method for seismic upgrading of damaged or poorly detailed $\mathrm{RC}$ construction. The main goal is to prevent shear damage in columns and to achieve flexural yielding and sufficient ductility. Figure 6a shows the retrofitted cross section for a central column in the fourth story. The size of all columns of the considered frame increased from $356 \mathrm{~mm} \times 508 \mathrm{~mm}$ to $508 \mathrm{~mm}$ by 660 $\mathrm{mm}$ with a jacket thickness of $76 \mathrm{~mm}$. Column concrete used for jacketing has nominal strength of $f^{\prime}{ }_{c} 34.5 \mathrm{MPa}$ in the first and second stories and $27.6 \mathrm{MPa}$ from the third story to the seventh. All steel reinforcement in jackets has a yield strength of $414 \mathrm{MPa}$ (Grade 60). Columns jackets include ten \#9 bars between ground and second floor; eight \#9 bars between second and fourth floors; ten \#7 bars between fourth and fifth floors; eight \#7 between fifth and seventh floors. The ties are \#4 bars spaced at $305 \mathrm{~mm}$ on center between ground and third floor and \# 3 bars spaced at $305 \mathrm{~mm}$ on center above the third floor. The retrofit design and reinforcement details meet the seismic provisions of ACI 318 [32]. Previous reinforcement in existing columns is neglected in the analysis. Table 1 shows the change in failure mode categories defined in the previous section. It is noted that all retrofitted columns tend to have flexural critical mechanism. Moreover, the first period of the frame shifted from 1.17 seconds for the bare frame to 0.93 seconds for the $\mathrm{RC}$ jacketed frame model.

\subsection{Shear wall}

The second retrofit method involved addition of a new shear wall into the frame to increase the strength and stiffness and to reduce demand on the unstrengthened columns, by limiting the lateral frame displacement. The wall is centered on the frame and is doweled into the existing columns and beams. Figure $6 \mathrm{~b}$ shows the shear wall cross section in the fourth floor. The boundary elements of the wall over the height of the entire frame are designed to be the 
retrofitted existing columns. After the RC jacketing, all boundary elements are $508 \mathrm{~mm}$ wide by $660 \mathrm{~mm}$ deep, i.e., oriented to bend in their weak direction when resisting lateral forces in the plane of the frame. Column concrete used for jacketing has nominal strength $f^{\prime} c$ of 34.5 $\mathrm{MPa}$ in the first and second stories, and $27.6 \mathrm{MPa}$ from the third story to roof. Grade 60 column reinforcing steel is used for jacketing $\left(f_{y}=414 \mathrm{MPa}\right)$. The shear wall outside boundary elements has a constant thickness of $200 \mathrm{~mm}$. The horizontal and vertical reinforcement ratios are determined following the minimum requirements in ACI 318 [32]. The fundamental period of the frame with shear wall is 0.46 seconds.

\subsection{FRP wrapping}

In the third retrofit application, the nonductile concrete columns of the frame are wrapped with carbon fiber reinforced polymer composite (CFRP) as shown in Figure 6c. All columns are wrapped with only one layer of uni-axial transverse CFRP, with a thickness of $0.164 \mathrm{~mm}$. The most common goal of use of CFRP retrofit is to increase shear strength and to prevent shear failure in columns. In addition, the CFRP can improve the deformation capacity, by providing confinement. Nevertheless, the improvement in the ultimate deformation and concrete strength maybe not be significant compared to increase in shear strength. The calculation of the shear strength and ductility increase are calculated using the Eurocode 8 [33] and Italian Guidelines [34]. The first period of the FRP retrofitted frame is 1.13 seconds. The FRP retrofitted models do not include fracture or debonding of the fiber wrap since these failure modes are assumed to be prevented during design and detailing. Table 1 shows that FRP wrap shifts the brittle failure modes to more ductile flexure failure. It is noted that, however, all RC jacketed or FRP wrapped columns have flexure dominated failure mechanisms.

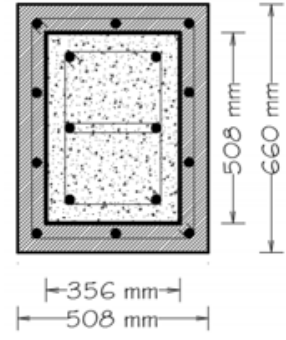

(a)

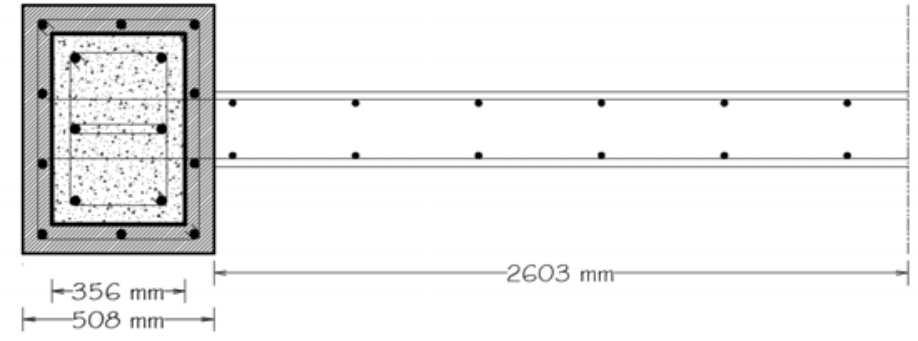

(b)

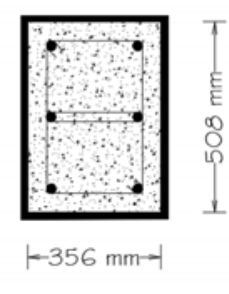

(c)

Figure 6 Retrofit options considered: a) RC jacketing of columns, b) shear wall addition and c) FRP wrapping of columns

\section{NONLINEAR ANALYSIS PROCEDURE AND RESULTS}

As described in [13], for each nonlinear time-history analysis, the corresponding critical demand to capacity ratio $\left(D C R_{P L}\right)$, equal to the mechanism that brings the structure closest to the onset of the performance level $P L$, is adopted as the structural response parameter. The $D C R P L$ parameter is defined as:

$$
D C R_{P L}=\max _{l}^{N_{\text {mech }}} \min _{j}^{N_{l}} \frac{D_{j l}}{C_{j l}(P L)}
$$

where $N_{\text {mech }}$ is the number of considered potential failure mechanisms; $N_{l}$ is the number of components taking part in the $l^{\text {th }}$ mechanism; $D_{j l}$ and $C_{j l}(P L)$ are the seismic demand (expressed herein in terms of chord rotation $\theta_{\text {demand }}$ ) and capacity for component $l$ at each (time) step $j$ of the analysis, respectively. $C_{j l}$ is calculated from the total capacity curve for each member end, corresponding to a prescribed performance levels PL (described in detail below). 
Seismic capacity in this work is characterized by: $\theta_{\text {yielding }}$ which is the deformation capacity corresponding to the point in which the longitudinal steel rebar in the member starts to yield in tension; $\theta_{\text {ultimate }}$ which is the deformation capacity corresponding to the point in which there is a $20 \%$ reduction in the strength on the softening branch in the total lateral response of the member; $\theta_{\text {axial }}$ which is the deformation capacity corresponding to complete loss of vertical load carrying capacity of the member.

The potential failure mechanisms considered here correspond to the achievement of the columns deformation capacities mentioned above and are the following: a) yielding of the columns: $\theta_{\text {demand }}>\theta_{\text {yielding; }}$, b) ductile or brittle failure of the columns: $\theta_{\text {demand }}>\theta_{\text {ultimate, }}$, depending on if the column is flexure or shear critical; and c) collapse of the columns: $\theta_{\text {demand }}>\theta_{\text {axial }}$. It is important to highlight the relationship between the failure mechanisms described above and the performance levels chosen in this work as suggested in Table C2.1 of ASCE 41 [16]. Performance levels are related to the achievement of objectives: a) yielding of the columns correspond to Immediate Occupancy performance level corresponding to hazard level identified with return period $T_{R}=72$ years; $b$ ) the ductile or brittle failures of the columns correspond to Life Safety performance level corresponding to hazard level identified with return period $T_{R}=225$ years; and c) the collapse of the columns correspond to Collapse Prevention performance level corresponding to hazard level identified with return period $\mathrm{T}_{\mathrm{R}}=975$ years.

The structural fragility is calculated based on the critical demand to capacity ratios $D C R_{P L}$ for a suite of un-scaled ground motion records for the above-mentioned three performance objectives (a.k.a., the Cloud Analysis). For a suite of ground motions, the cloud data encompasses pairs of ground motion intensity measure (IM) and its corresponding structural performance variable $D C R_{P L}$ (see Eq.3). Herein, IM is adopted as the spectral acceleration at the first-mode period, $S_{a}\left(T_{1}\right)$. When predicting nonlinear response of structures, it is necessary to account for the possibility that some records may cause collapse of the structure at higher levels of IM, which sometimes is manifested by numerical non-convergence in the analysis software. It is however important to note that achieving a $D C R_{P L}$ greater than unity at ultimate limit state does not necessarily entail structural collapse. In this research, the criteria established by [35] for defining global structural collapse is adopted, where the structural collapse occurs when one of the two following conditions has reached: 1) $50 \%+1$ of the columns in only one story reach $\theta_{\text {axial }}$; and 2) the maximum lateral interstory drift exceeds $10 \%$. Therefore, the cloud data is divided into two parts: a) $\mathrm{NoC}$ data which correspond to that portion of the suite of records for which the structure does not experience global "Collapse", and b) $C$ data for which the structure will experience "Collapse". The fragility, defined as the probability of exceeding the limit state PL given IM, more conveniently expressed as the probability that $D C R_{P L}$ exceeds unity given IM, can be expanded with respect to $N o C$ and $C$ portions of cloud data using total probability theorem $[12,36]$ :

$$
P\left(D C R_{P L}>1 \mid S_{a}\right)=P\left(D C R_{P L}>1 \mid S_{a}, N o C\right) \times P\left(N o C \mid S_{a}\right)+P\left(D C R_{P L}>1 \mid S_{a}, C\right) \times P\left(C \mid S_{a}\right)
$$

The probability terms in Eq. (4) are described as:

$\square$ The $N o C$ term $P\left(D C R_{P L}>1 \mid S_{a}, N o C\right)$ is the conditional probability that $D C R P L$ exceeds unity for a given value of spectral acceleration $S_{a}$ conditioned on $N o C$. It can be described by a lognormal distribution, where various studies have illustrated that this assumption is adequate for describing a displacement-based engineering demand parameter given IM [37-40]:

$$
P\left(D C R_{P L}>1 \mid S_{a}, N o C\right)=P\left(\ln D C R_{P L}>0 \mid S_{a}, N o C\right)=\Phi\left(\frac{\ln \eta_{D C R_{P L} \mid S_{a}, N o C}}{\beta_{D C R_{P L} \mid S_{a}, N o C}}\right)
$$

where $\Phi$ is the standardized Gaussian cumulative distribution function (CDF), $\eta_{D C R P L S a, N o C}$ and $\beta_{D C R P L} \mid S a, N o C$ are conditional median and logarithmic standard deviation (dispersion) of the natural logarithm of $D C R_{P L}$ given $N o C$. Based on the standard Cloud Analysis procedure, 
these two parameters can be obtained by performing a logarithmic linear regression (i.e., linear regression in the logarithmic scale) on the $\mathrm{NoC}$ portion of data:

$$
\ln \eta_{D C R_{P L} \mid S_{a}, N o C}=\ln a+b \ln \left(S_{a}\right), \beta_{D C R_{P L} \mid S_{a}, N o C}=\sqrt{\frac{\sum_{\Omega_{N o C}}\left(\ln D C R_{P L}-\ln a-b \ln \left(S_{a}\right)\right)^{2}}{N_{N o C}-2}}
$$

where $N_{N o C}$ is the number of non-collapse-inducing $(N o C)$ records.

$\square$ The term $P\left(D C R_{P L}>1 \mid S_{a}, C\right)$ is equal to unity, i.e., in the cases of global dynamic instability (global Collapse), the performance level $P L$ is certainly exceeded.

글 the term $P\left(C \mid S_{a}\right)=1-P\left(N o C \mid S_{a}\right)$ is the probability of global dynamic instability (global Collapse), which can be expressed by a logistic regression model (a.k.a., logit) on the $S a$ values of the entire cloud data [41]:

$$
P\left(C \mid S_{a}\right)=\frac{1}{1+e^{-\left(\beta_{0}+\beta_{1} \cdot S_{a}\right)}}
$$

where $\beta_{0}$ and $\beta_{1}$ are the parameters of the logistic regression. It should be noted that the logistic regression model is particularly useful for cases in which the dependent variable of regression is binary (i.e., can have only two values 1 and 0 , yes or no, which is the case of $C$ and $N o C$ herein). Eq. (5) can also be used in order to calculate the demand value, $D C R_{P L}$, corresponding to percentile $p$ of the distribution $P_{D C R \mid S a}$ (i.e., the $p \%$ demand value) by setting the left side of the Eq. (5) equal to $p$ and solving it for $D C R^{p}{ }_{P L}[42]$ :

$$
y_{L S}^{p}=\eta_{Y_{L S} \mid S_{a}, N o C} \cdot \exp \left(\beta_{Y_{L S} \mid S_{a}, N o C} \cdot \Phi^{-1}\left(\frac{p}{P\left(N o C \mid S_{a}\right)}\right)\right)
$$

where $\Phi^{-1}$ is the inverse function of standardized normal distribution. In particular, considering only $N o C$ data where $P\left(N o C \mid S_{a}\right)$ becomes 1 in Eq.(8), while taking into account collapse information ( $C$ data), $P\left(N o C \mid S_{a}\right)$ is estimated based on the logistic regression model Eq. (7).

\subsection{Pushover results}

Nonlinear static or pushover analysis of the frame is performed to determine its overall frame stiffness, strength and damage progression under increasing lateral forces. In this research, lateral load is applied using an inverse triangular load distribution using a force base approach in OpenSees. The response in terms of lateral loads (e.g., base shear) and maximum interstory drift is monitored.

In Figure 7, the static pushover results are presented for the bare frame and the three retrofitted frame models. The events of the first column yielding, attainment of the first column ultimate capacity and the axial failure of the first column are shown in Figure 7 for each model. As explained above, the failure mechanisms of first yielding, first ultimate capacity and first axial failure can be defined to correspond, respectively, to immediate occupancy, life safety and collapse prevention performance levels, as described in [16]. According to FEMA 356 [43], these three performance levels are identified by the lateral drift thresholds of $1 \%$, $2 \%$ and $4 \%$. Figure 7 shows that, in particular for the bare frame, these limits at first yielding, first ultimate capacity and first axial failure, match relatively well with the pushover results. 


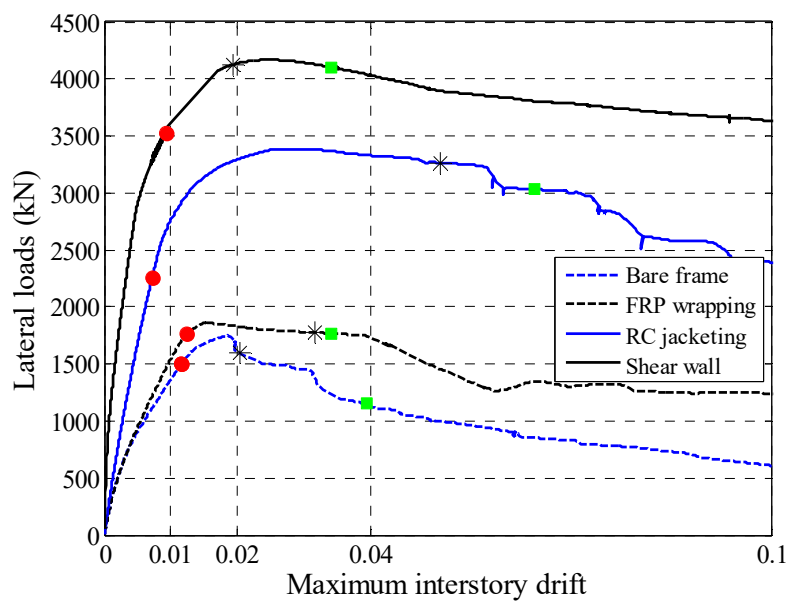

Figure 7 Pushover curves for bare frame and retrofitted frames (circles show the first member yielding, stars show the first ultimate capacity achievement and squares show the first axial failure in the frame)

Table 2 shows the calculated yield strength, $V_{y}$; maximum strength, $V_{\max }$; ultimate strength, $V_{u}$; axial strength, $V_{a}$ and global ductility for each of the frame model. Ductility, $\mu$, is calculated as the ratio of maximum interstory drift of the frame at the collapse level and maximum interstory drift corresponding to the first member yielding. Table 3 compares strength and ductility at first yielding, first column ultimate capacity and first column axial failure for bare and retrofitted frames, where $\mu_{u}$ and $\mu_{a}$ are the ductility values at the first ultimate capacity achievement and at the first axial failure in the frame. This allows for direct comparison of structural performance of each of the retrofit strategies. Table 3 shows that the addition of shear wall increases the strength most while the largest ductility increase is achieved when columns are jacketed. Both strength and ductility increase (can decrease at axial failure) is the smallest for FRP retrofitted frame.

\begin{tabular}{|c|c|c|c|c|c|}
\hline Case & $V_{y}(\mathrm{kN})$ & $V_{\max }(\mathrm{kN})$ & $V_{u}(\mathrm{kN})$ & $V_{a}(\mathrm{kN})$ & Ductility $\mu$ \\
\hline Bare frame & 1499 & 1744 & 1603 & 1152 & 3.38 \\
\hline RC jacketing & 2252 & 3385 & 3265 & 3033 & 9.03 \\
\hline Shear wall & 3525 & 4169 & 4125 & 4102 & 10.75 \\
\hline FRP wrap & 1759 & 1863 & 1776 & 1768 & 2.75 \\
\hline
\end{tabular}

Table 2 Yield strength $\left(V_{y}\right)$, maximum strength $\left(V_{\max }\right)$, ultimate strength $\left(V_{u}\right)$, axial strength $(V a)$ and global ductility for each model

\begin{tabular}{|c|c|c|c|c|c|}
\hline \multirow{3}{*}{ Case } & First yielding & \multicolumn{2}{|c|}{ First ultimate failure } & \multicolumn{2}{c|}{ First axial failure } \\
\cline { 2 - 6 } & $\begin{array}{c}\text { Strength } \\
V_{y} / V_{\text {y bare frame }}\end{array}$ & $\begin{array}{c}\text { Strength } \\
V_{u} / V_{u \text { bare frame }}\end{array}$ & $\begin{array}{c}\text { Ductility } \\
\mu_{u} / \mu_{u \text { bare frame }}\end{array}$ & $\begin{array}{c}\text { Strength } \\
V_{a} / V_{\text {a bare frame }}\end{array}$ & $\begin{array}{c}\text { Ductility } \\
\mu_{a} / \mu_{\text {a bare frame }}\end{array}$ \\
\hline RC jacketing & 1.50 & 2.04 & 4.00 & 2.63 & 2.66 \\
\hline Shear wall & 2.35 & 2.57 & 1.20 & 3.56 & 1.08 \\
\hline FRP wrap & 1.17 & 1.11 & 1.47 & 1.53 & 0.82 \\
\hline
\end{tabular}

Table 3 Comparison of response of bare and retrofitted frames in terms of strength and ductility at first yielding, first ultimate capacity achievement and first axial failure in the frame

\subsection{Cloud Analysis}

A set of 70 strong ground-motion records are selected from the NGA-West2 database [44] in order to implement cloud analysis. This suite of records covers a wide range of magnitudes between 5.5 and 7.9, and closest distance-to-ruptured area (denoted as $R_{R U P}$ ) up to around 40 $\mathrm{km}$, as illustrated by the scatter diagram in Figure 8a. The spectral acceleration spectra for the 
selected suite of ground motion records are shown in Figure $8 \mathrm{~b}$. Since the shear wave velocity in upper $30 \mathrm{~m}$ of soil, $V s 30$, at the structure's site is around $218 \mathrm{~m} / \mathrm{sec}$, all selected records are chosen to be on NEHRP site classes C-D (where C: $360<V s 30<760 \mathrm{~m} / \mathrm{s}$ and D: $180<V s 30 \leq 360 \mathrm{~m} / \mathrm{s}$ ). No limits have been set (in this selection) on the number of recordings from a single seismic event, while only one of the two horizontal components of each recording, with higher spectral acceleration at around $1.0 \mathrm{sec}$, is selected. By setting the lowest cut off frequency equal to $0.25 \mathrm{~Hz}$, it has been ensured that the low-frequency content is not removed by the ground motion filtering process. There is no specific consideration on the type of faulting; nevertheless, the selected records are from strike-slip or reverse faults (consistent with active tectonic zones). The records are selected to be free field or on the ground level without consideration of station housing.

(a)
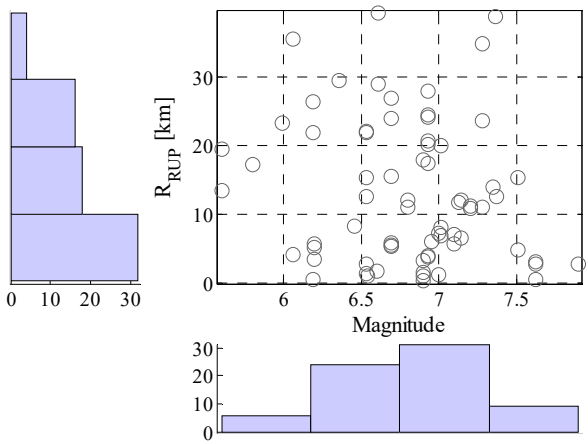

(b)

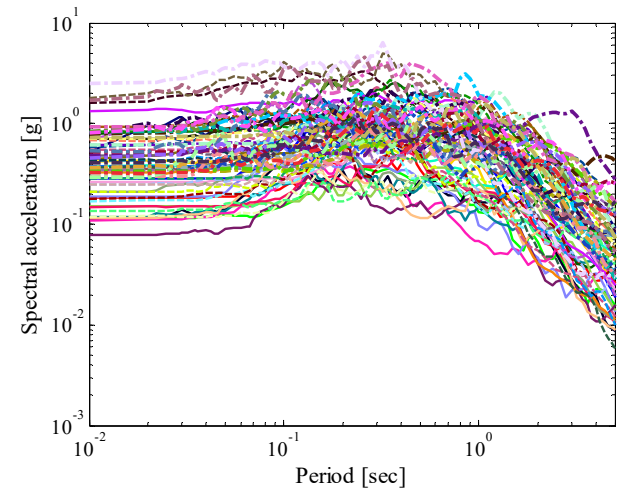

Figure 8 a) Scatter diagram, and b) response spectra, for the suite of ground-motion records used for cloud analysis.

The "cloud" method provides estimates of the two statistical parameters of demand given the spectral acceleration, namely the median given spectral acceleration $\eta_{D C R P L} \mid S a$ and the (constant) logarithmic standard deviation given spectral acceleration $\beta_{D C R P L S a}$. The "cloud" response is obtained by applying original ground motions (as recorded) to the structure. Once the ground motion records are applied to the structure, the resulting $D C R_{P L}=D / C$ are calculated for each performance level. As explained above, it is necessary to account for the possibility that some records may cause collapse of the structure at higher levels of IM. To account for these collapse cases, the cloud data is partitioned into collapsed and not-collapsed cases. In particular, in the case that none of the ground motion records selected leads to collapse, the fragility defined as $\mathrm{P}\left(D C R_{P L}>1 \mid S_{a}\right)$ can be estimated from Eq. (5) based on the logarithmic linear regression on the entire cloud data. Alternatively, if $C$ data exist, the fragility is calculated by implementing Eq. (4) where the logarithmic linear regression is applied to the $\mathrm{NoC}$ portion of cloud data and the logistic regression is applied to the entire cloud data. Figures 9, 10, 11 and 12 show the cloud analysis results for the different performance levels for each model and illustrate the $16^{\text {th }}, 50^{\text {th }}$ and $84^{\text {th }}$ percentiles of the performance variable as a function of spectral acceleration and calculated from Eq. (8). The figures also report the parameters of the logarithmic linear regression (considering only the non-collapsed cases), namely, $\log a, b$ and standard deviation $\beta_{D C R P L} \mid S a, N_{O} C=\beta$. 

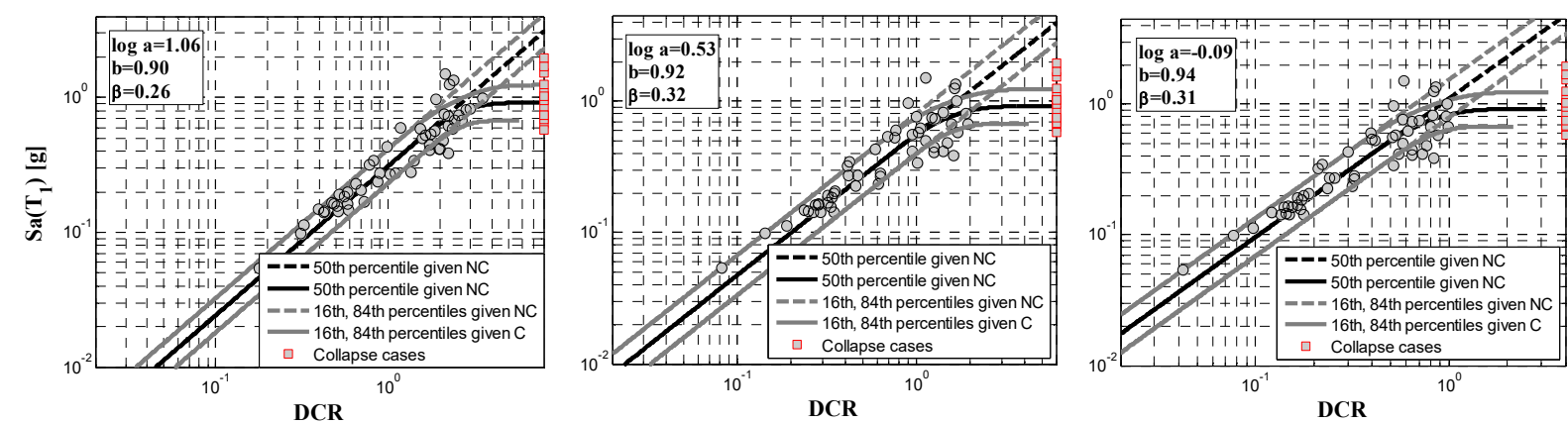

Figure 9 Cloud regression for bare frame: a) immediate occupancy PL, b) life safety PL, and c) collapse prevention PL
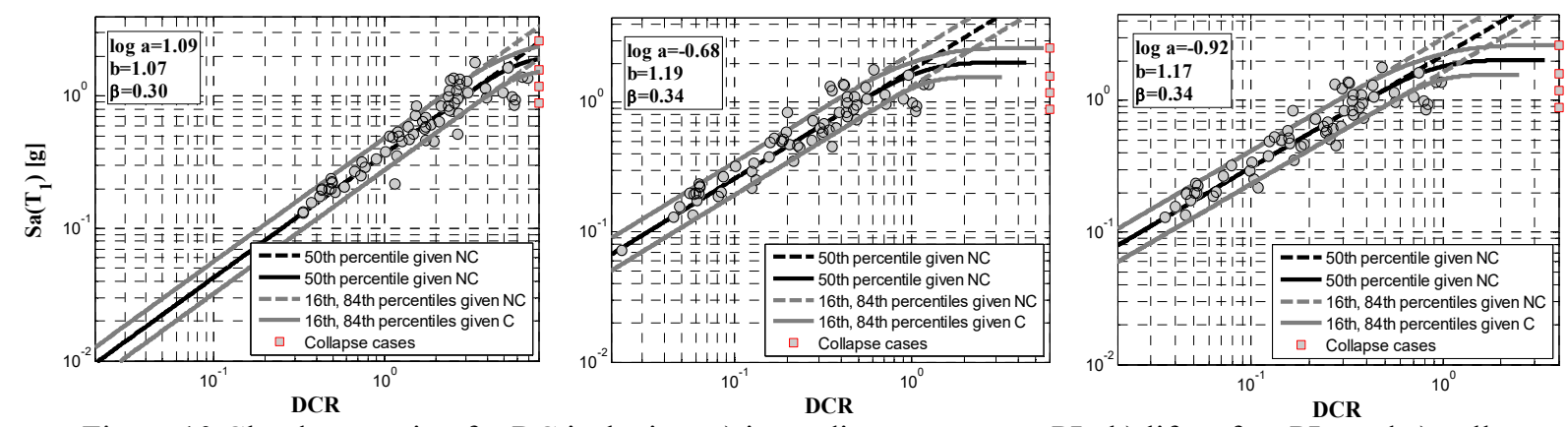

Figure 10 Cloud regression for RC jacketing: a) immediate occupancy PL, b) life safety PL, and c) collapse prevention PL
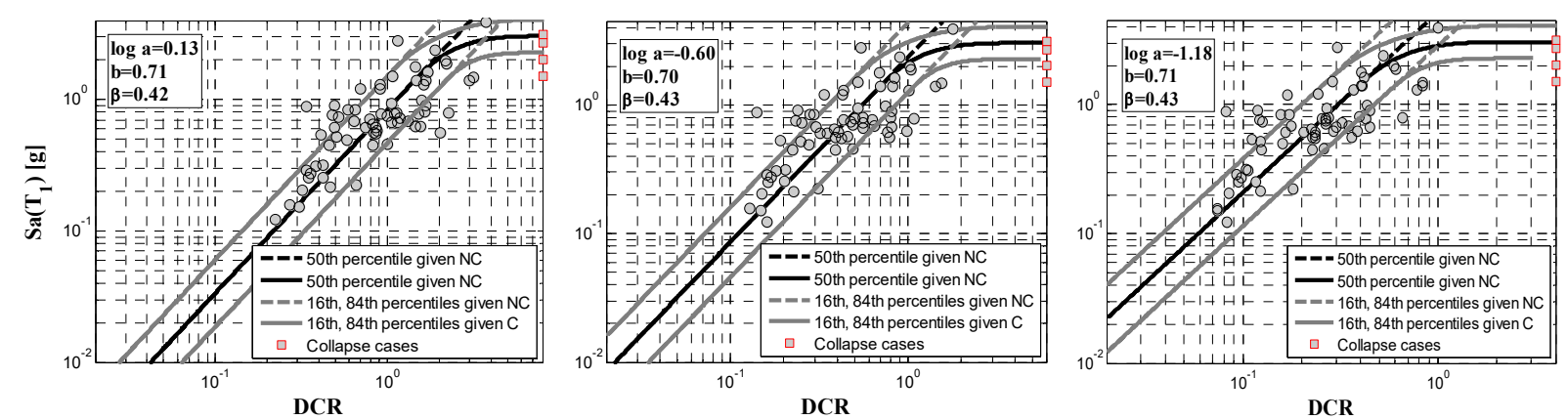

Figure 11 Cloud regression for shear wall: a) immediate occupancy PL, b) life safety PL, and c) collapse prevention $\mathrm{PL}$
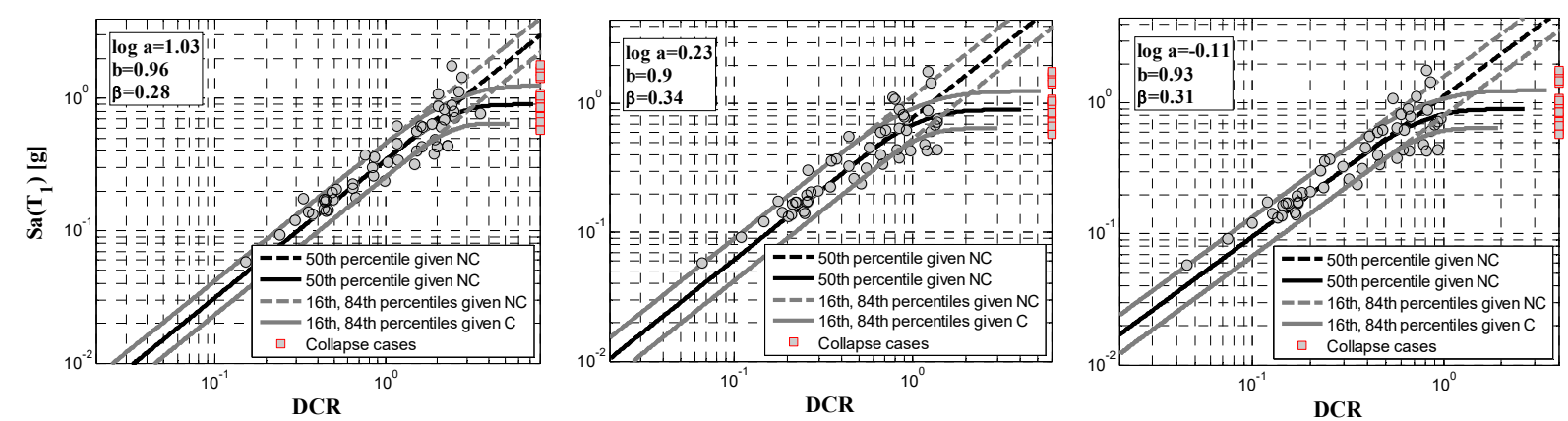

Figure 12 Cloud regression for FRP wrapping: a) immediate occupancy PL, b) life safety PL, and c) collapse prevention PL 


\subsection{Performance-based safety-checking}

As described in [45], a framework for probability-based demand and capacity factor design $(D C F D)$ seismic safety evaluation is implemented in order to verify the structural safety at each performance level. The $D C F D$ format is based on a closed-form analytical expression for the mean annual frequency of exceeding a structural performance level. The threshold for each performance level is identified by a critical demand to capacity ratio $D C R P L$ calculated for the prescribed performance level (e.g., immediate occupancy, life safety or collapse prevention) and set equal to unity. According to $D C F D$, the structure in question satisfies the safety requirements for a prescribed performance level $P L$ if the seismic demand corresponding to an acceptable probability/risk level is less than or equal to the seismic capacity for that $P L$. Herein, an intensity-based version of this format is adopted where the safety criteria is expressed in term of the seismic intensity measure [see 46]:

$$
S_{a}\left(P_{o}\right) \leq S_{a}^{P L}
$$

where $S_{a}\left(P_{o}\right)$ or the IM-based factored demand (denoted generically later as DPL, where $P L=I O, L S, C P)$ is the spectral acceleration value corresponding to the acceptable probability level $P_{o}$, based on the site-specific mean hazard curve (https://www.usgs.gov) for the fundamental period of the frame (Figure 12). The hazard curve is approximated by a power-law type of expression in the region of spectral acceleration values of interest:

$$
S_{a}\left(P_{o}\right)=\lambda_{S_{a}}^{-1}\left(P_{o}\right) ; \lambda_{S_{a}}\left(S_{a}\right) \approx k_{o} \cdot S_{a}^{-k}
$$

where $k_{o}$ and $k$ are the fit parameters with $k$ that is the slope of this approximate curve. $S_{a} P L$ (denoted generically later as $C_{P L}$, where $P L=I O, L S, C P$ ) is the IM-based factored capacity and is calculated as:

$$
S_{a}^{P L}=\eta\left(S_{a}^{D C R_{P L}=1}\right) \cdot \exp \left(-\frac{k}{2} \beta\left(S_{a}^{D C R_{P L}=1}\right)^{2}\right)
$$

where $S_{a}{ }^{D C R_{P L}=1}$ is the spectral acceleration at the onset of performance level $P L$ (i.e., $\left.D C R_{P L}=1\right) ; \eta\left(S_{a}{ }^{D C R_{P L}=1}\right)$ and $\beta\left(S_{a}{ }^{D C R_{P L}=1}\right)$ are the median and logarithmic standard deviation of the fragility curve for performance level PL. The fragility is defined as $\mathrm{P}\left(D C R_{P L}>1 \mid S_{a}\right)$ or equivalently in IM-based terms as $\mathrm{P}\left(S_{a}{ }^{D C R_{P L}}=1 \leq S_{a}\right)$ is assumed to be a lognormal cumulative distribution function (CDF) with median $\eta\left(S_{a}{ }^{D C R P L=1}\right)$ and logarithmic standard deviation $\beta\left(S_{a}{ }^{D C R_{P L}=1}\right)$ estimated as:

$$
\eta\left(S_{a}{ }^{D C R_{P L}=1}\right)=S_{a}^{50 t h} ; \quad \beta\left(S_{a}{ }^{D C R_{P L}=1}\right)=\frac{1}{2} \ln \frac{S_{a}^{84 t h}}{S_{a}^{16 t h}}
$$

where $S_{a}{ }^{16 t h}, S_{a}{ }^{50 t h}, S_{a}{ }^{84 t h}$ are the values of $S_{a}$ corresponding to probability values equal to 0.16 , 0.50 and 0.84 , respectively. As it can be seen from the precedent equation, the capacity factor, $\exp \left(k \beta^{2}\left(S_{a}{ }^{D C R_{P L}=1}\right) / 2\right)$ is a reduction factor that takes into account the record-to-record variability in the structural performance capacity (expressed in IM-based terms). In other words, the factored capacity is always less than or equal to the median capacity. Figures 13, 14 and 15 show the hazard and the fragility curves and the calculation of $D_{P L} S_{a}\left(P_{o}\right)$ and $C_{P L}=S_{a}{ }^{P L}$ for each performance level for each modeling option. Tables 4 and 5 show the statistical parameters for fragility curves and the comparison between $D_{P L}$ and $C_{P L}$, respectively, for each modeling option in each performance level. Based on these results in term of structural performance, it is possible to evaluate the effectiveness of the different retrofit options. Moreover, in Miano et al. [47], a cost analysis is also presented in order to compare the estimates of expected life cycle cost for each of the retrofit methods considered in this case study. 

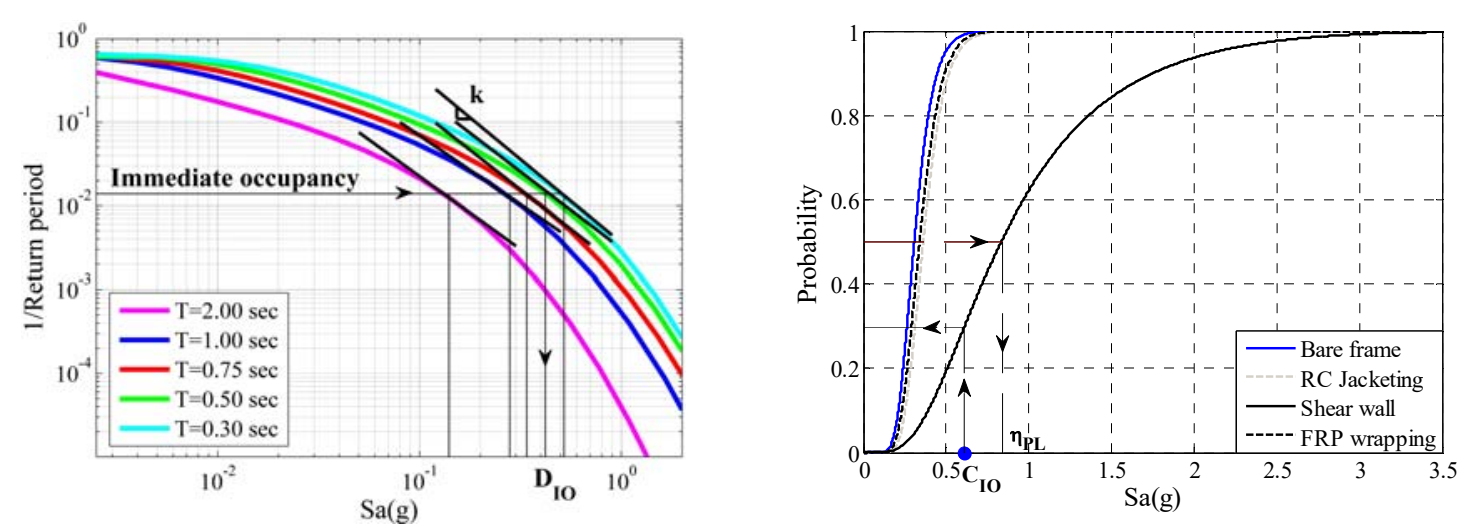

Figure 13 Hazard and fragility curves for immediate occupancy performance level (PL=IO)
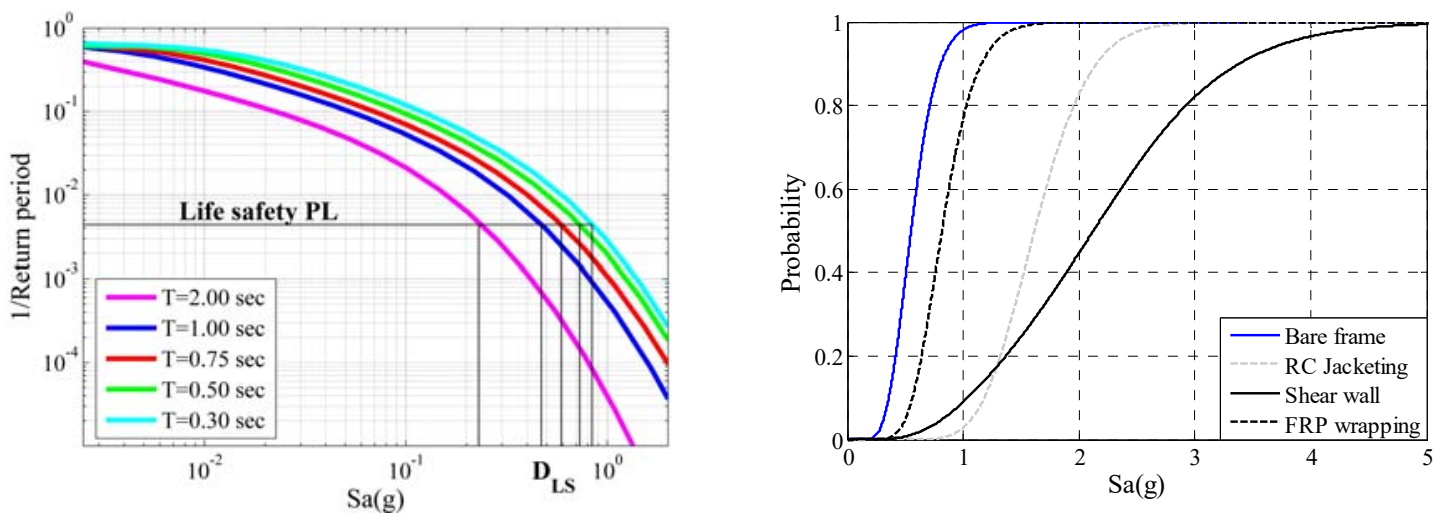

Figure 14 Hazard and fragility curves for life safety performance level (PL=LS)
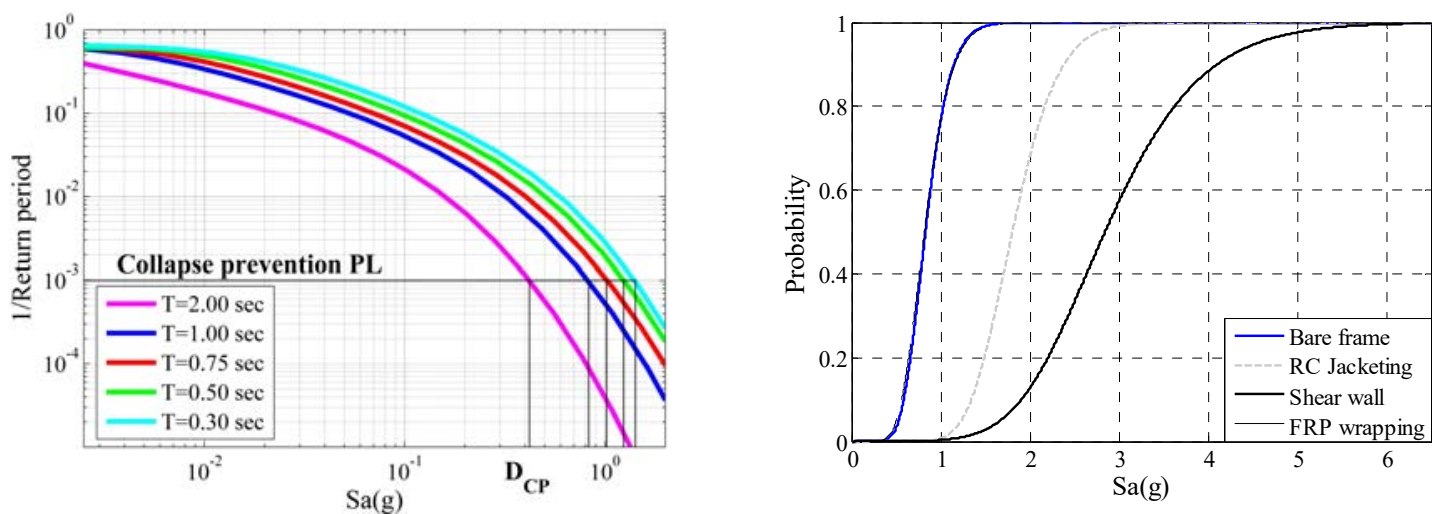

Figure 15 Hazard and fragility curves for collapse prevention performance level $(\mathrm{PL}=\mathrm{CP})$

\begin{tabular}{|c|c|c|c|c|c|c|}
\hline & \multicolumn{2}{|c|}{ Immediate occupancy } & \multicolumn{2}{c|}{ Life safety PL } & \multicolumn{2}{c|}{ Collapse prevention PL } \\
\hline Model & $\eta(g)$ & $\beta$ & $\eta(g)$ & $\beta$ & $\eta(g)$ & $B$ \\
\hline Bare frame & 0.30 & 0.29 & 0.55 & 0.32 & 0.82 & 0.27 \\
\hline RC jacketing & 0.37 & 0.28 & 1.61 & 0.23 & 1.81 & 0.22 \\
\hline Shear wall & 0.84 & 0.57 & 2.12 & 0.44 & 2.84 & 0.29 \\
\hline FRP wrapping & 0.34 & 0.29 & 0.68 & 0.29 & 0.82 & 0.27 \\
\hline
\end{tabular}

Table 4 Statistical parameters for fragility curve

\begin{tabular}{|c|c|c|c|c|c|c|c|}
\hline Model & $S a\left(T_{1}\right)(\mathrm{g})$ & $D_{I O}(\mathrm{~g})$ & $C_{I O}(\mathrm{~g})$ & $D_{L S}(\mathrm{~g})$ & $C_{L S}(\mathrm{~g})$ & $D_{C P}(\mathrm{~g})$ & $C_{C P}(\mathrm{~g})$ \\
\hline Bare frame & 1.17 & 0.27 & 0.27 & 0.45 & 0.48 & 0.78 & 0.73 \\
\hline RC jacketing & 0.93 & 0.30 & 0.34 & 0.51 & 1.51 & 0.89 & 1.68 \\
\hline Shear wall & 0.54 & 0.44 & 0.61 & 0.75 & 1.65 & 1.28 & 2.48 \\
\hline FRP wrapping & 1.13 & 0.27 & 0.32 & 0.45 & 0.62 & 0.78 & 0.73 \\
\hline
\end{tabular}

Table 5 Comparison between DPL and CPL for each modelling option in each performance level 


\section{CONCLUSIONS}

In this paper, alternative retrofit methods are evaluated for older nonductile frame buildings using a nonlinear structural performance assessment methodology. As a case study, the north longitudinal frame of an existing hotel building is modeled including the effect of flexural-shear-axial load interaction to be able to capture column shear and axial failures. As a probabilistic nonlinear dynamic analysis framework, cloud method is used since it is particularly efficient, involving nonlinear analyses of the structure subjected to a set of un-scaled ground motion time histories. A framework for probability-based demand and capacity factor design $(D C F D)$ seismic safety evaluation is implemented in order to verify the structural performance and safety at each chosen performance level. Based on this cloud analysis framework, a risk based retrofit strategy optimization is developed in this study. The structural performance is the main parameter taken into account for the optimization.

This study shows that it is crucial to choose the most effective retrofit strategy based on the performance assessment of the bare frame. A fundamental point in the assessment is the necessity to accurately model materials and column members (considering also specific shear and slip models) to capture the flexure, shear and flexure-shear failure modes in columns and the potential collapse of the building frame. Another important point is the possibility to use the critical demand to capacity ratio $(D C R P L)$ as structural performance parameter for each performance level, which is defined by the mechanism that brings the structure closest to the onset of the specific performance level $P L$.

The final results show that it is crucial to choose a retrofit strategy based on the safety assessment of the bare frame. Each retrofit strategy can improve the performance of the existing building differently based on how much it can increase the ductility and/or strength and avoid the brittle mechanisms. Considering most columns in the hotel building analyzed are not likely to fail in pure shear, FRP retrofit is expected to be less effective than the other retrofit options. This is because FRP wrapping generally leads to a significant increase mostly in shear resistance. On the contrary, both $\mathrm{RC}$ jacketing and shear wall retrofit options provide the bare frame with additional strength and stiffness and lead to a factored capacity that is approximately four times that of the bare frame, for both life safety and near collapse PLs. However, for the immediate occupancy $P L, \mathrm{RC}$ jacketing does not lead to a significant increase in capacity, while the frame with shear wall achieves a factored capacity about four times that of the bare frame.

\section{ACKNOWLEDGMENTS}

The first author visited the Ohio State University to conduct part of the present research and was funded by the University of Naples Federico II. The support is gratefully acknowledged.

\section{REFERENCES}

[1] F. Zareian, H. Krawinkler, Assessment of probability of collapse and design for collapse safety. Earthquake Engineering \& Structural Dynamics, 36(13), 1901-1914, 2007.

[2] L. Eads, E. Miranda, H. Krawinkler, D.G. Lignos, An efficient method for estimating the collapse risk of structures in seismic regions. Earthquake Engineering and Structural Dynamics, 42(1), 25-41, 2013.

[3] H. Sezen, A. Whittaker, K. Elwood, K. Mosalam, Performance of reinforced concrete buildings during the August 17, 1999 Kocaeli, Turkey earthquake, and seismic design and construction practise in Turkey. Engineering Structures, 25(1), 103-114, 2003. 
[4] A.B. Liel, C.B. Haselton, G.G. Deierlein, J.W. Baker, Incorporating modeling uncertainties in the assessment of seismic collapse risk of buildings. Structural Safety, 31(2), 197-211, 2009.

[5] O.C. Celik, B.R. Ellingwood, Seismic fragilities for non-ductile reinforced concrete frames-Role of aleatoric and epistemic uncertainties. Structural Safety 32(1): 1-12, 2010 .

[6] S.H. Jeong, A.M. Mwafy, A.S. Elnashai, Probabilistic seismic performance assessment of code-compliant multi-story RC buildings. Engineering Structures, 34, 527-537, 2012.

[7] F. Zareian, P. Kaviani, E. Taciroglu, Multiphase Performance Assessment of Structural Response to Seismic Excitations. Journal of Structural Engineering, 141(11), 04015041, 2015.

[8] C.A. Cornell, F. Jalayer, R.O. Hamburger, D.A. Foutch, Probabilistic basis for 2000 SAC federal emergency management agency steel moment frame guidelines. Journal of Structural Engineering, 128(4), 526-533, 2002.

[9] N. Shome, C.A. Cornell, P. Bazzurro, J.E. Carballo, Earthquakes, records, and nonlinear responses. Earthquake Spectra, 14(3), 469-500, 1998.

[10] D. Vamvatsikos, C.A. Cornell, Incremental dynamic analysis. Earthquake Engineering and Structural Dynamics, 31(3), 491-514, 2002.

[11] J.W. Baker, C.A. Cornell, A vector-valued ground motion intensity measure consisting of spectral acceleration and epsilon. Earthquake Engineering and Structural Dynamics, 34(10), 1193-1217, 2005.

[12] F. Jalayer, C.A. Cornell, Alternative non-linear demand estimation methods for probability-based seismic assessments. Earthquake Engineering and Structural Dynamics, 38(8): 951-972, 2009.

[13] F. Jalayer, P. Franchin, P. Pinto, A scalar damage measure for seismic reliability analysis of RC frames. Earthquake Engineering and Structural Dynamics, 36(13), 2059-2079, 2007.

[14] F. Jalayer, R. De Risi, G. Manfredi, Bayesian Cloud Analysis: efficient structural fragility assessment using linear regression. Bulletin of Earthquake Engineering, 13(4), 11831203, 2005.

[15] F. Jalayer, H. Ebrahimian, A. Miano, G. Manfredi, H. Sezen, Analytical fragility assessment using un-scaled ground motion records. Earthquake Engineering and Structural Dynamics, 2017; (Submitted).

[16] American Society of Civil Engineers (ASCE 41-13), Seismic Evaluation and Retrofit of Existing Buildings, 2013.

[17] M.S. Islam, Analysis of the Northridge earthquake response of a damaged non-ductile concrete frame building. The structural design of tall buildings, 5(3), 151-182, 1996.

[18] J. Browning, Y.R. Li, A. Lynn, J.P. Moehle, Performance assessment for a reinforced concrete frame building. Earthquake Spectra, 16(3), 541-555, 2000. 
[19] H. Krawinkler, Van Nuys hotel building testbed report: exercising seismic performance assessment. Pacific Earthquake Engineering Research Center, University of California, Berkeley, 2005.

[20] M.D. Trifunac, S.S. Ivanovic, M.I. Todorovska, Instrumented 7-storey reinforced concrete building in Van Nuys, California: description of the damage from the 1994 Northridge Earthquake and strong motion data. Report CE 99 2, 1999.

[21] F. De Luca, G.M. Verderame, A practice-oriented approach for the assessment of brittle failures in existing reinforced concrete elements. Engineering Structures 48, 373-388, 2013.

[22] F. McKenna, OpenSees: a framework for earthquake engineering simulation. Computing in Science and Engineering, 13(4), 58-66, 2011.

[23] E.J. Setzler, H. Sezen, Model for the lateral behavior of reinforced concrete columns including shear deformations. Earthquake Spectra, 24(2), 493-511, 2008.

[24] H.E. Roy, M.A. Sozen, A model to simulate the response of concrete to multi-axial loading. University of Illinois Engineering Experiment Station. University of Illinois, 1963.

[25] J.B. Mander, M.J. Priestley, R. Park, Theoretical stress-strain model for confined concrete. Journal of structural engineering, 114(8), 1804-1826, 1988.

[26] M.H. Scott, G.L. Fenves, Plastic hinge integration methods for force-based beamcolumn elements. Journal of Structural Engineering, 132(2), 244-252, 2006.

[27] H. Sezen, J.P. Moehle, Shear strength model for lightly reinforced concrete columns. Journal of Structural Engineering, 130(11), 1692-1703, 2004.

[28] H. Sezen, Shear deformation model for reinforced concrete columns. Structural Engineering and Mechanics, 28(1), 39-52, 2008.

[29] M. Gerin, P. Adebar, Accounting for shear in seismic analysis of concrete structures. Proc., 13th World Conference on Earthquake Engineering, 1-6, 2004.

[30] K.J. Elwood, J.P. Moehle, Axial capacity model for shear-damaged columns. ACI Structural Journal, 102, 578-587, 2005.

[31] H. Sezen, J.P. Moehle, Bond-slip behavior of reinforced concrete members. Fib Symposium on Concrete Structures in Seismic Regions, CEB-FIP, 2003.

[32] American Concrete Institute (ACI 318-14), Building Code Requirements for Structural Concrete, 2014.

[33] Eurocode 8 Design of structures for earthquake resistance, 2007.

[34] Linee guida per la Progettazione, l'Esecuzione ed il Collaudo di Interventi di Rinforzo di strutture di c.a., c.a.p. e murarie mediante FRP-Guidelines for Design, Execution and Test of retrofit interventions for concrete and masorny structures using FRP, 2009.

[35] P.H. Galanis, J.P. Moehle, Development of Collapse Indicators for Risk Assessment of Older-Type Reinforced Concrete Buildings. Earthquake Spectra, 31(4), 1991-2006, 2015.

[36] N. Shome, C.A. Cornell, Probabilistic seismic demand analysis of nonlinear structures. Report No. RMS35, Stanford University, CA, 1996. 
[37] J. Song, B.R. Ellingwood, Seismic reliability of special moment steel frames with welded connections: II. Journal of Structural Engineering, 125.4: 372-384, 1999.

[38] M. Shinozuka, M.Q. Feng, J. Lee, T. Naganuma, Statistical analysis of fragility curves. Journal of engineering mechanics, 126(12), 1224-1231, 2000.

[39] K. Porter, R. Kennedy, R. Bachman, Creating fragility functions for performance-based earthquake engineering. Earthquake Spectra, 23(2), 471-489, 2007.

[40] B.A. Bradley, R.P. Dhakal, Error estimation of closed-form solution for annual rate of structural collapse. Earthquake Engineering and Structural Dynamics, 37(15): 17211737, 2008.

[41] F. Jalayer, H. Ebrahimian, Seismic risk assessment considering cumulative damage due to aftershocks. Earthquake Engineering and Structural Dynamics, 46(3), 369-389, 2016.

[42] F. Jalayer, Direct Probabilistic seismic analysis: implementing non-linear dynamic assessments. Ph.D. dissertation, Stanford University, California, 2003.

[43] FEMA 356, Prestandard and Commentary for the Seismic Rehabilitation of Buildings, 1997.

[44] T.D. Ancheta, R.B. Darragh, J.P. Stewart, E. Seyhan, W.J. Silva, B.S.J. Chiou, K.E. Wooddell, R.W. Graves, A.R. Kottke, D.M. Boore, NGA-West2 database. Earthquake Spectra, 30(3), 989-1005, 2014.

[45] F. Jalayer, C.A. Cornell, A technical framework for probability-based demand and capacity factor design (DCFD) seismic formats. Technical Report PEER 2003/08, Berkeley, USA, 2003.

[46] F. Jalayer, S. Carozza, R. De Risi, G. Manfredi, E. Mbuya, Performance-based flood safety-checking for non-engineered masonry structures. Engineering Structures, 106, 109-123, 2016.

[47] A. Miano, H. Sezen, F. Jalayer, A. Prota, Performance based comparison of effectiveness of building retrofit methods. Earthquake Spectra, 2017 (Submitted). 